\title{
Willingness to pay for community-based health insurance and associated factors among rural households of Bugna District, Northeast Ethiopia
}

\author{
Amare Minyihun ${ }^{1 *}\left(\mathbb{D}\right.$, Measho Gebreslassie Gebregziabher ${ }^{2}$ and Yalemzewd Assefa Gelaw ${ }^{3}$
}

\begin{abstract}
Objective: Community based health insurance schemes are becoming recognized as powerful method to achieve universal health coverage and reducing the financial catastrophic shock of the community. Therefore, this study aimed to assess willingness to pay for community-based health insurance and associated factors among rural households of Bugna District, Ethiopia.

Results: A total of 532 study participants were included in the study. The finding indicated that $77.8 \%$ of the households were willing to pay for the community-based health insurance. The average amount of money the households were willing to pay per household per annum was 233 ETB (\$11.12 USD). The result of the study also revealed that attending formal education $[\beta=3.20 ; 95 \% C l=1.87,4.53]$, history of illness $[B=2.52 ; 95 \% C l=1.29,3.75]$, household size $[B=0.408 ; 95 \% \mathrm{Cl}=0.092,0.724]$, awareness about the scheme $[B=2.96 ; 95 \% \mathrm{Cl}=1.61,4.30]$, and wealth status $[\beta=5.55 ; 95 \% \mathrm{Cl}=4.19,6.90]$ were factors significantly associated with willingness to pay. Therefore, enhancing awareness of the community about the scheme, considering the amount of premium as per household family size and wealth status might increase household's willingness to pay for community-based health insurance.
\end{abstract}

Keywords: Community based health insurance, Willingness to pay, Tobit model, Bugna district, Ethiopia

\section{Introduction}

Globally, 150 million people per year suffer from financial catastrophic shock, and 100 million are pushed into poverty because of direct payments for health services. In the majority of African countries, more than $40 \%$ of their total health expenditure was constituted by out-of-pocket payment (OPP) and this resulted in scarcity of funds for health [1]. As a result of this, developing health financing system was a common agenda for all countries [2-4].

In Ethiopia OPP accounts 37\% of the total spending in health care. This leads to financial catastrophic shock [5]. To overcome these challenges an efficient and equitable

\footnotetext{
*Correspondence: amarebdr@gmail.com

${ }^{1}$ Department of Health Systems and Policy, Institute of Public Health, College of Medicine and Health Sciences, University of Gondar, P.o. Box: 196, Gondar, Ethiopia

Full list of author information is available at the end of the article
}

health care financing strategy was formulated [6]. The immediate goals of universal health coverage (UHC) are access, utilization and financial protection, while health status is a longer-term indirect result (although probably the ultimate goal), and one of the key strategies is reducing direct payments [2].

The government of Ethiopia has introduced Community Based Health Insurance (CBHI) as strategy for reducing financial catastrophic shock in our country, and it has been piloted in selected districts of the country. The utilization of scheme by the community members were affected by different factors such as socio-demographic, economic and health related factors [7].

A pilot study in Ethiopia has indicated that the scheme provides a benefit package of all available services in the health centres and hospitals excluding tooth implantation and eyeglasses with the provider payment mechanism 
of fee-for-service. Accordingly, the membership for the scheme could be all core family members $[8,9]$.

According to the Health Sector Financing Reform (HSFR) project report, the overall enrollment in the pilot schemes was $48 \%$. It varies from district to district and ranges from 25\% in Deder to 100\% in Yirgalem, and households registered as indigents is $7 \%$, and ranges from $1 \%$ in Deder to $15 \%$ in Tehuledere and Yirgalem [10].

Understanding the community's willingness to pay (WTP) for the CBHI and determining the amount of money is useful for policy makers to implement the program and to expand the program nationally. Therefore, the objective of this study was to assess the WTP for CBHI and associated factors among rural households in Bugna District, Ethiopia.

\section{Main text \\ Methods}

Community based cross-sectional study was conducted from February to March, 2016 among households in Bugna district. Bugna district is found in Amhara National Regional State which is $354 \mathrm{~km}$ far from Bahir Dar (capital city of the region). The district has thirteen rural and one urban kebele. According to the district health office report, it has a population of 91,750 in 2016 [11]. The district has 4 health centers and 13 health posts that provide health service for the dwellers.

All households in the rural kebele of district were the source population whereas all households in the selected rural kebele of the district were the study population. Those permanent residents of the community with household head aged 18 years and above were included in the study. Households with heads or spouses that have been employed in the formal sectors were excluded from the study.

The sample size of the study was calculated using single population proportion formula with the assumption of; proportion of WTP for CBHI in Fogera district $(\mathrm{p}=80 \%)$ [12]. The total sample size was 541 after considering $95 \%$ confidence level, $5 \%$ margin of error, design effect of 2 and $10 \%$ non-response rate.

Multi-stage systematic sampling technique was employed to select study participants. First, five out of 13 rural kebeles were selected using lottery method. Then, the sample was proportionally allocated among the selected kebeles based on the number of the households. Finally, systematic random sampling technique was used to select participants.

The dependent variable was WTP for CBHI, whereas socio- demographic characteristics (age, sex, marital status, educational status, family size, religion and ethnicity), economic factors(wealth index and occupation); environmental factors (distance from health institution in walking time); health and health-related factors (health condition of illness, chronic illness and disability, medical treatment for the recent episode, health care cost of the recent treatment, perceived quality of the health care service in the area); knowledge related factors(awareness about $\mathrm{CBHI}$ and social trust were independent variables of the study. The CBHI scheme (insurer) covers all costs of the members related to transportation, drugs, laboratory tests, hospitalization, and other necessary imaging examinations, but expenses of some selected chronic non-infectious diseases such as diabetes mellitus, heart failure, cancer, and treatment from abroad weren't covered by the insurance. WTP for CBHI was measured using the bid contingent value method through asking a specific amount of money (180 ETB), and probing the question using a higher or lower bid value depending on the respondent's response to the first question until the maximum amount of money participants were WTP. A pre-tested and standardized questionnaire was used to collect the data. Most of the tools were adapted from the previous studies of Benchi Maji [13] and Fogera [12]. The wealth item questions were adapted from the Ethiopian Health Insurance Agency CBHI evaluation report [8]. Pre- test was done on $10 \%$ of the subjects at Lasta District.

The collected data were cleaned, coded, entered into EPI-INFO version 7 software and exported and analysed using STATA software package version 14. Variables with p-value of less than 0.2 during bivariate analysis were considered for the multiple regression analysis [14-16]. Regression coefficient with $95 \% \mathrm{CI}, \mathrm{t}$-value and p-value were used to measure the strength association.

Tobit model was used to identify factors associated with WTP and the maximum amount of money that individuals were WTP. This model has an advantage over other discrete choice models (linear, logistic, and probit) in that, it reveals both the probability of WTP and the maximum amount of money the respondents are WTP.

$$
\mathrm{y}= \begin{cases}1 & \text { if } M W T P=\beta_{0}+\beta^{\prime} X i+\mathrm{e}>0 \\ 0 & \text { if } M W T P \leq 0\end{cases}
$$

where $\mathrm{y}=$ outcome; $\mathrm{MWTP}=$ Maximum willingness to pay; $\mathrm{X} i=$ explanatory variables; $\beta_{0}=$ Slope, $\beta^{\prime}=$ Coefficient; $\mathrm{e}=$ error term; $0=$ No and $1=$ yes.

The model also estimates marginal effect of an explanatory variable on the expected value of the dependent variable. A p-value $=0.05$ was used to determine statistical significance.

\section{Results \\ Socio-demographic characteristics of households}

A total of 532 participants participated in the study with response rate of $97.4 \%$. The median age (IQR) of 
the respondents was 35 (14) years, ranging from 18 to 75 years. The majority of respondents were males $(66 \%)$, farmer (70.3\%), illiterate (55.3\%). Moreover, $71.6 \%$ of the participants were married and the mean family size of the participants were $4.8( \pm 1.8)$ (Table 1$)$.

\section{Health related characteristics of study participants}

One hundred ninety-six (36.5\%) respondents evaluated their family's health status as medium. Eighty-seven (16.4\%) of the member of the households had at least one member with chronic illness while $41.0 \%$ had at least one member who had encountered acute illnesses 3 months prior to data collection. The median expenditure of the 145 households which got treatments was 60 ETB with range of 10 to 1500 ETB. Sixty-eight (46.9\%) of these households reported that it was difficult to cover payments for treatments. As a result, $43.4 \%$ of them have borrowed money from someone to cover their medical costs (Table 2).

The mean amount of money household heads willing to pay was $233.3 \mathrm{ETB}(95 \% \mathrm{CI}=225.6,241.4)$ per house hold annually or 11.1 USD (Additional files 1 and 2).

\section{Factors associated with willingness to pay for $C B H I$}

For each an additional household member, the WTP value of households was increased by 0.4 USD other conditions being held constant $(ß=0.408,95 \%$ CI $(0.092$, $0.724)$.

The study also revealed that respondents who attended formal education were WTP 3.2 USD more than those who didn't attend formal education, holding other variables constant $(ß=3.20,95 \%$ CI $(1.87,4.53)$.

Table 1 Demographic and socio-economic characteristics of study participants in Bugna District, North East Ethiopia, $2016(n=532)$

\begin{tabular}{|c|c|c|c|}
\hline Variables & Description & Number & Percent $(95 \% \mathrm{Cl})$ \\
\hline \multirow[t]{2}{*}{ Sex of the respondent } & Male & 351 & $65.9(61.8,69.8)$ \\
\hline & Female & 181 & $34.1(30.1,38.1)$ \\
\hline \multirow[t]{5}{*}{ Age of the respondents } & $\leq 29$ years & 153 & $28.8(25.1,32.7)$ \\
\hline & $30-39$ years & 184 & $34.6(30.6,38.7)$ \\
\hline & $40-49$ years & 133 & $25.0(21.4,28.8)$ \\
\hline & $50-59$ years & 40 & $7.5(5.5,10.0)$ \\
\hline & 60 years and above & 22 & $4.1(2.7,6.2)$ \\
\hline \multirow[t]{4}{*}{ Marital status of respondents } & Single & 38 & $7.1(5.2,9.6)$ \\
\hline & Married & 433 & $81.4(77.8,84.4)$ \\
\hline & Windowed & 8 & $1.5(0.7,2.9)$ \\
\hline & Divorced & 53 & $10.0(7.6,12.8)$ \\
\hline \multirow[t]{5}{*}{ Occupation of the respondents } & Farmer & 374 & $70.3(66.2,74.0)$ \\
\hline & Housewife & 82 & $15.4(12.5,18.7)$ \\
\hline & Merchant & 46 & $8.6(6.5,11.3)$ \\
\hline & Daily labourer & 8 & $1.6(0.8,3.0)$ \\
\hline & Students & 22 & $4.1(2.7,6.2)$ \\
\hline \multirow[t]{4}{*}{ Educational status } & Unable to read and write & 294 & $55.3(50.9,59.4)$ \\
\hline & Read and write & 122 & $29.9(19.5,26.7)$ \\
\hline & Primary education & 93 & $17.5(14.4,20.9)$ \\
\hline & Secondary education & 23 & $4.3(2.8,6.4)$ \\
\hline \multirow[t]{2}{*}{ Family size } & $\leq 5$ & 308 & $57.9(53.5,61.9)$ \\
\hline & $>5$ & 224 & $42.1(38.0,46.4)$ \\
\hline \multirow[t]{3}{*}{ Household having children $<5$ years old } & No child & 136 & $25.6(22.0,29.4)$ \\
\hline & One child & 250 & $47.0(42.7,51.2)$ \\
\hline & 2 and above & 146 & $27.4(23.8,31.4)$ \\
\hline \multirow[t]{2}{*}{ Household having a person above 65 years old age } & No older age & 464 & $87.2(84.0,89.8)$ \\
\hline & One and above & 68 & $12.8(10.1,15.9)$ \\
\hline \multirow[t]{3}{*}{ Wealth quintile of the household } & Poor (1st quintile) & 172 & $32.3(28.4,36.4)$ \\
\hline & Medium (2nd quintile) & 182 & $34.2(30.2,38.3)$ \\
\hline & Rich (3rd quintile) & 178 & $33.5(29.5,37.5)$ \\
\hline
\end{tabular}


Table 2 Health related characteristics of study participants in Bugna district, 2016

\begin{tabular}{|c|c|c|c|}
\hline Variable & Description & Number & Percent $(95 \% \mathrm{Cl})$ \\
\hline \multirow[t]{5}{*}{ Self-reported health status of HHs $(n=532)$} & Very poor & 11 & $2.1(1.1,3.7)$ \\
\hline & Poor & 72 & $13.5(10.8,16.7)$ \\
\hline & Medium & 196 & $36.5(32.8,41.0)$ \\
\hline & Good & 189 & $35.5(31.5,39.7)$ \\
\hline & Very good & 64 & $12.4(9.5,15.0)$ \\
\hline \multirow[t]{2}{*}{ Chronic illness $(n=532)$} & No & 445 & $83.6(80.2,86.5)$ \\
\hline & Yes & 87 & $16.4(13.4,19.7)$ \\
\hline \multirow[t]{2}{*}{ Any illness during the past 3 months $(n=532)$} & No & 314 & $59.0(54.7,63.1)$ \\
\hline & Yes & 218 & $41.0(36.8,45.2)$ \\
\hline \multirow[t]{2}{*}{ Get treatment $(n=218)$} & No & 73 & $33.5(29.5,37.5)$ \\
\hline & Yes & 145 & $66.5(58.6,74.7)$ \\
\hline \multirow[t]{2}{*}{ Coverage of the health care cost $(n=145)$} & Self & 135 & $93.1(87.5,96.2)$ \\
\hline & Free/community or Gov. & 10 & $6.9(3.3,11.9)$ \\
\hline \multirow[t]{5}{*}{ Satisfaction with health care service and costs $(n=145)$} & Very dissatisfied & 4 & $2.7(1.0,7.1)$ \\
\hline & Dissatisfied & 11 & $7.6(4.2,13.2)$ \\
\hline & Neutral & 13 & $9.0(5.2,14.9)$ \\
\hline & Satisfied & 88 & $60.7(52.4,68.3)$ \\
\hline & Very satisfied & 29 & $20.0(14.2,27.3)$ \\
\hline \multirow[t]{5}{*}{ Perceived quality of the health care service in the district $(n=145)$} & Very low & 3 & $2.0(0.6,6.2)$ \\
\hline & Low & 12 & $8.3(4.7,14.0)$ \\
\hline & Medium & 12 & $8.3(4.7,14.0)$ \\
\hline & High & 89 & $61.4(53.1,69.0)$ \\
\hline & Very high & 29 & $20.0(14.2,27.3)$ \\
\hline \multirow[t]{3}{*}{ Concern of the $\mathrm{HH}$ for covering health care costs $(n=145)$} & Very difficult & 28 & $19.3(13.6,26.6)$ \\
\hline & Difficult & 68 & $46.9(38.8,55.1)$ \\
\hline & Not difficult & 49 & $33.8(26.4,41.9)$ \\
\hline \multirow[t]{2}{*}{ Borrow money for medical costs $(n=145)$} & No & 82 & $56.6(51.9,60.4$ \\
\hline & Yes & 63 & $43.4(33.8,47.6)$ \\
\hline \multirow[t]{4}{*}{ Home distance from health centre or hospital in minutes } & $<30 \min$ & 132 & $24.8(21.3,28.6)$ \\
\hline & 30-min to $1 \mathrm{~h}$ & 185 & $34.8(30.8,38.9)$ \\
\hline & $1 h \leq 2 h$ & 121 & $22.7(17.1,29.9)$ \\
\hline & $>2 \mathrm{~h}$ & 94 & $17.7(14.6,21.1)$ \\
\hline
\end{tabular}

Households who had awareness about the scheme were WTP 2.9 USD more than those who had no awareness about the scheme, holding other variables constant $(ß=2.96,95 \%$ CI $(1.61,4.30)$.

Households who had history of illness in household member were WTP 2.5 USD more than the counter factual, holding other variables constant $(\beta=2.52,95 \%$ CI (1.61, 4.30). Similarly, households with higher economic status were WTP 5.5 USD more than those who are in lower socioeconomic status, holding other variables constant $(ß=5.55,95 \%$ CI $(4.19,6.90)$ (Table 3; Additional file 3).

\section{Discussion}

This study aimed to assess WTP for CBHI and associated factors among households in Bugna district, Northeast Ethiopia. About $77.8 \%$ of participants were WTP for CBHI. The average amount of money WTP per household per annum was 233 ETB $(\$ 11.12$ USD) for proposed CBHI. This implies the communities were WTP higher money than the proposed payment during the study period which was 140 up to 195 ETB. But the amount of money respondents WTP was consistent with the newly proposed premium which is 240 . The mean amount of money WTP in the study is greater than study in Nigeria [17] and Ethiopia [9]. However, this was lower than study done in Cameroon [18], Nigeria [19], Namibia [20], Bangladesh [21] and Burkina Faso [22]. The discrepancy might be 
Table 3 Maximum likely hood of Tobit econometric analysis of factors associated with WTP for CBHI in Bugna district, 2016

\begin{tabular}{|c|c|c|c|c|c|c|c|}
\hline Parameter for MWTP & Category & $\begin{array}{l}\text { Unadjusted } \\
\text { coefficient }\end{array}$ & $\begin{array}{l}\text { adjusted } \\
\text { coefficients }\end{array}$ & Standard error & t-value & p value & $95 \%$ Conf. interval \\
\hline Age & N & 1.02 & 0.03 & 0.026 & 1.39 & 0.166 & $-0.015,0.007$ \\
\hline Households family size & $\mathrm{N}$ & 12.69 & 0.40 & 0.160 & 2.54 & $0.011^{*}$ & $0.092,0.724$ \\
\hline Educational status (ref. informal) & $\mathrm{D}$ & & & & & & \\
\hline Formal education & & 36.66 & 3.20 & 0.676 & 4.74 & $0.000^{*}$ & $1.87,4.53$ \\
\hline Awareness about the CBHIS (ref. poor awareness) & $\mathrm{D}$ & & & & & & \\
\hline Good awareness & & 75.25 & 2.96 & 0.685 & 4.32 & $0.000^{*}$ & $1.61,4.30$ \\
\hline Social trust among them (ref. poor trust) & $\mathrm{D}$ & & & & & & \\
\hline Good trust & & 7.42 & 1.20 & 0.756 & 1.60 & 0.111 & $-0.27,2.69$ \\
\hline Chronic illness in household member (ref. no) & $\mathrm{D}$ & & & & & & \\
\hline Have chronic illness & & 11.62 & -0.05 & 0.804 & -0.07 & 0.942 & $-1.63,1.52$ \\
\hline $\begin{array}{l}\text { History of any Illness in household member (ref. } \\
\text { no) }\end{array}$ & $\mathrm{D}$ & & & & & & \\
\hline Have illness & & 19.30 & 2.52 & 0.626 & 4.03 & $0.000^{*}$ & $1.29,3.75$ \\
\hline $\begin{array}{l}\text { Home distance from health centre or hospital in } \\
\text { time (ref }<30 \mathrm{~min})\end{array}$ & $\mathrm{D}$ & & & & & & \\
\hline 30-min to $1 \mathrm{~h}$ & & -23.15 & -2.71 & 1.850 & -1.46 & 0.144 & $-6.34,0.92$ \\
\hline $1 \mathrm{~h} \leq 2 \mathrm{~h}$ & & -16.85 & -0.001 & 0.653 & -0.00 & 0.999 & $-1.28,1.28$ \\
\hline$>2 \mathrm{~h}$ & & 11.32 & 0.99 & 0.827 & 1.21 & 0.229 & $-0.62,2.62$ \\
\hline Perceived health status (ref poor) & $\mathrm{D}$ & & & & & & \\
\hline Medium & & 7.26 & -0.54 & 0.829 & -0.65 & 0.514 & $-2.17,1.08$ \\
\hline Good & & 6.05 & -0.56 & 0.864 & -0.66 & 0.511 & $-2.26,1.13$ \\
\hline Wealth quintile of the household (ref poor) & $\mathrm{D}$ & & D & & & & \\
\hline Medium (2nd quintile) & & 27.22 & 2.10 & 0.668 & 3.14 & $0.002^{*}$ & $0.78,3.41$ \\
\hline Rich (3rd quintile) & & 85.00 & 5.55 & 0.691 & 8.03 & $0.000^{*}$ & $4.19,6.90$ \\
\hline Constant & & & -0.93 & 1.59 & -0.59 & 0.559 & $-4.07,2.20$ \\
\hline Sigma & & & 5.90 & 0.21 & & & $5.48,6.33$ \\
\hline
\end{tabular}

$\mathrm{D}$, dummy variable $(0,1) ; \mathrm{N}$, numeric value

* Significant with $p$-value $\leq 0.05$

due to the difference in study period, area, design and participants.

The study revealed that households with larger family sizes were WTP a higher amount compared to households with smaller family size. This finding is supported by other studies conducted in Nigeria [17], Ethiopia [8], Bangladesh [21], china [23], and India [24]. The possible explanation might be as a result of the huge financial burden faced by households with a large size when they seek health care services.

Educational status of the respondents was found to be another factor to increase the amount of premiums WTP for CBHI scheme. This is consistent with a studies done in Nigeria [25], Cameron [18] and Burkina Faso [22]. Educated household heads have better knowledge about the advantage of making regular insurance payments to avoid the risk of catastrophic medical expenditures at the time of illness.
Respondent's awareness about the CBHI had positive and significant association with WTP for the CBHI. This finding was consistent with studies conducted in Nigeria [26], Cameron [27], and Myanmar [28]. This might be due to knowing the catastrophic effects of health problem and the benefits of joining the insurance scheme earlier.

The wealth status of the families had positive and significant association with WTP. Which is similar with other studies conducted inEthiopia [12], Nigeria [19], Bangladesh [21], China [29], St. Vincent [30], and India [24]. The possible explanation might be having more wealth is associated with high asset losses if an unexpected event occurs that leads to be households more WTP for the insurance than the poorer.

The history of illness in the last 3 months in household members had significant effect to WTP for the CBHI. This finding was consistent with other studies in India [24], and Bangladesh [21]. This might be due 
to the risk-averse individuals are more likely to enrol in the insurance.

Political will and governmental commitment towards the scheme were the opportunities for CBHI implementation in the country. Accordingly, the presence of clear action plans, national scope of implementation and existence of regulatory frameworks were the strengths before introducing and start to implement the scheme. On the contrary, the decision for CBHI enrollment was made at the kebele level as opposed to the household level and a general subsidy from the federal government is also provided for all scheme members without giving especial emphasis for those members who cannot afford to pay. Furthermore, premium load was decided only by their family size without considering their level of income were the limitations of the scheme $[8,9]$.

Overall, this finding indicated that the proportion of households willing to pay for the scheme was low as compared to the goal of UHC. WTP for CBHI were influenced by educational status, history of illness, family size, awareness and wealth status of the households. Therefore, the government had better to consider the household family size and wealth status for setting the premium load. Moreover, strengthening awareness creation at the community about the scheme to enhance utilization of the scheme.

\section{Limitation}

Even though this study lies on the large sample size with high response rate, the study has its own limitation on response biases which may overestimate or underestimate the results of WTP due to the use of self-reporting.

\section{Additional files}

Additional file 1: Figure S1. Relationship ship of Maximum willingness to pay and the Premium level. In this study, As the premium level decreases the probability to pay for the community-based health increase. At low premium levels nearly, all study participants were willing to pay that premium or vice versa. The distribution of maximum willing ness to pay for the newly proposed community-based health insurance scheme in the rural households of Bugna district, 2016.

Additional file 2: Table S1. A bivariable with the proportion of WTP for $\mathrm{CBHI}$ and mean amount with $95 \% \mathrm{Cl}$. In this study the mean amount of money willing to pay for $\mathrm{CBH}$ for females' respondents were 239.66 ETB, and age of respondent between 40 and 49 years were 240.29 ETB. The mean amount of WTP for CBHI for those respondents who have married, farmer, and unable to read and write were 239.91, 235.08 and 216.37 ETB, respectively. The mean amount of willing to pay of the proposed scheme for those respondents who have family member greater than five were 256.78; and those respondents who have been in the 3 rd quantile of the wealth index were 302.42 ETB.

Additional file 3: Table S2. The marginal effect of factors associates with willingness to pay for $\mathrm{CBH}$. The result shows that when the family size of a household increases by one person, it will increase the probability of willingness of a household to pay for community-based health insurance by $1.12 \%[d y / d x=0.0112,95 \% \mathrm{Cl}(0.002,0.020)]$. The marginal effect of this variable reveals that respondents who had formal education $7.3 \%$ more probability of paying for community-based health insurance compared to respondents who did not have formal education $[\mathrm{dy} / \mathrm{dx}=0.0730,95 \% \mathrm{Cl}$ $(0.045,0.100)]$. The marginal effect of this variable reveals that respondents who had awareness about the scheme were $7.07 \%$ more probability of paying for community-based health insurance compared to respondents who did not have awareness about the scheme $[\mathrm{dy} / \mathrm{dx}=0.0707,95 \% \mathrm{Cl}$ $(0.043,0.097)]$. The marginal effect of this variable reveals that respondents who had history of illness in household member were $6.71 \%$ more probability of paying for community-based health insurance compared to respondents who did not have history of illness in the household member $[d y / d x=0.0671,95 \% \mathrm{Cl}(0.034,0.099)]$. Marginal effect of factors associate with WTP for $\mathrm{CBH}$ after Tobit econometrical analysis in Bugna district, 2016.

\section{Abbreviations}

ANHB: Amhara Regional Health Bureau; CBHI: Community Based Health Insurance; CBHIS: Community-Based Health Insurance Scheme; DA: Developmental Agent; ETB: Ethiopian Birr; HEW: Health Extension Worker; NAD: Namibian Dollar; HSFR: Health Sector Financing Reform; OPP: out-of-pocket payment; UHC: Universal Health Coverage; \$ USD: Untied States of American Dollar; VCHI: Voluntary Community Health Insurance; WTP: willingness to pay.

\section{Authors' contributions}

AM conceived the original idea, involved in proposal writing, designed the study was responsible for data collection, analyzed the data and drafted of manuscript and participated in all phases of the project. MG supervised the research process contribute in its design and interpretation of the data and the results, involved in critically revising the manuscript. Moreover, MG participated at all stages of the research project. YA supervised the research process, participated in its design and interpretation of the data and the results, involved in revising the manuscript. YA participated at all stages of the research project. All authors read and approved the final manuscript.

\section{Author details}

${ }^{1}$ Department of Health Systems and Policy, Institute of Public Health, College of Medicine and Health Sciences, University of Gondar, P.o. Box: 196, Gondar, Ethiopia. ${ }^{2}$ Department of Health Systems, School of Public Health, College of Health Sciences, Mekelle University, Mekelle, Ethiopia. ${ }^{3}$ Department of Epidemiology and Biostatistics, Institute of Public Health, College of Medicine and Health Sciences, University of Gondar, Gondar, Ethiopia.

\section{Competing interests}

The authors declare that they have no competing interests.

\section{Acknowledgements}

We deeply express our gratefulness to University of Gondar for financial support without which this project would have not been possible. Our special thanks and sincere appreciation also goes to Amhara Regional Health Bureau, Bugna District Health office staff. Moreover, we would also give a gratitude for the study participants, data collectors and other individuals or organizations that has participated directly or indirectly into the study.

Availability of data and materials

Data will be available upon request from the corresponding author.

Consent to publish

Not applicable.

\section{Ethics approval and consent to participate}

The study was reviewed and approved by Ethical Review Board of the Institute of Public Health, College of Medicine and Health Science, and University of Gondar. Official letters of permission were also obtained from Amhara Regional Health Bureau, Bugna Health Office and the respective kebeles. After explaining the purpose and importance of the study, verbal informed consent was obtained from each study participant. Name of the respondent was not included in the questionnaire and the confidentiality of the data was kept at all level of the study. 


\section{Funding}

This study was funded by university of Gondar. The views presented in the article are the authors and not necessarily express the views of the funding organization. University of Gondar did not involve in the design of the study, data collection, analysis and interpretation.

\section{Publisher's Note}

Springer Nature remains neutral with regard to jurisdictional claims in published maps and institutional affiliations.

Received: 4 September 2018 Accepted: 14 January 2019

Published online: 24 January 2019

\section{References}

1. Adebayo EF, et al. A systematic review of factors that affect uptake of community-based health insurance in low-income and middle-income countries. BMC Health Serv Res. 2015;15:543.

2. Giedion U, Andrés Alfonso E, Díaz Y. The impact of universal coverage schemes in the developing world: a review of the existing evidence. Essex: Institute for Social and Economic Research; 2013.

3. Malik,K. Human development report 2014. Sustaining human progress: Reducing vulnerabilities and building resilience. New York: United Nations Development Programme.(http://hdr.undp.org/sites/default/files /hdr14-report-en-1.pdf), 2014

4. World Health Organization. State of health financing in the African Region. Geneva: World Health Organization; 2013.

5. FMOH E. Health and health related indicators report. 2003/2011G.C.

6. Asfaw A, von Braun J. Innovations in health care financing: new evidence on the prospect of community health insurance schemes in the rural areas of Ethiopia. Int J Health Care Finance Econ. 2005;5(3):241-53.

7. Dong $\mathrm{H}$, et al. The feasibility of community-based health insurance in Burkina Faso. Health Policy. 2004;69(1):45-53.

8. Ethiopian Health Insurance Agency. Evaluation of community-based health insurance pilot schemes in Ethiopia. Addis Ababa: Ethiopian Health Insurance Agency; 2015.

9. Mebratie A. et al. The impact of Ethiopia's pilot community based health insurance scheme on healthcare utilization and cost of care. ISS Working Paper Series/General Series, 2014. 593:1-46.

10. Alebachew A, et al. Ethiopia's Progress in health financing and the contribution of the 1998 health care and financing strategy in Ethiopia. MA, Addis Ababa: Harvard TH Chan School of Public Health and Breakthrough International Consultancy, PLC; 2015.

11. Bugna et al. Fiscal year annual report. 2007/2015. 2007.

12. Kebede Adane, et al. Willingness to pay for community based health insurance among households in the rural community of Fogera District. Int J Econ Finance Manag Sci. 2014;2(4):263-9.

13. Haile M, Ololo S, Megersa B. Willingness to join community-based health insurance among rural households of Debub Bench District, Bench Maji Zone, Southwest Ethiopia. BMC Public Health. 2014;14:591.
14. Tanha K, Mohammadi N Janani L. P-value what is and what is not. Med J Islam Repub Iran. 2017;31:65. https://doi.org/10.14196/mjiri.31.65.

15. Katz MH. Multivariable analysis: a practical guide for clinicians and public health researchers. Cambridge: Cambridge University Press; 2011.

16. Kim J, Bang HJDH. Three common misuses of $P$ values. Dent Hypotheses. 2016;7(3):73.

17. Babatunde $\mathrm{OA}$, et al. Willingness to pay for community health insurance and its determinants among household heads in rural communities in North-Central Nigeria. Int Rev Soc Sci Humanitie. 2012;2(2):133-42.

18. Donfouet HPP, et al. The determinants of the willingness-to-pay for community-based prepayment scheme in rural Cameroon. Int J Health Care Finance Econ. 2011;11(3):209-20.

19. Oriakhi H, Onemolease E, Amla R. Determinants of rural household's willingness to participate in community based health insurance scheme in Edo State, Nigeria. Stud Ethno-Med. 2012;6(2):95-102.

20. Gustafsson-Wright E, Asfaw A, van der Gaag J. Willingness to pay for health insurance: an analysis of the potential market for new low-cost health insurance products in Namibia. Soc Sci Med. 2009:69(9):1351-9.

21. Ahmed S, et al. Willingness-to-pay for community-based health insurance among informal workers in Urban Bangladesh. PLOS ONE. 2016;11(2):e0148211.

22. Dong $\mathrm{H}$, et al. Willingness-to-pay for community-based insurance in Burkina Faso. Health Econ. 2003;12(10):849-62

23. Wang $\mathrm{H}$, et al. Community-based health insurance in poor rural China: the distribution of net benefits. Health Policy Plan. 2005;20(6):366-74.

24. Mathiyazaghan K. Willingness to pay for rural health insurance through community participation in India. Int J Health Plan Manag. 1998;13(1):47-67

25. Odeyemi IA. Community-based health insurance programmes and the national health insurance scheme of Nigeria: challenges to uptake and integration. Int J Equity Health. 2014;13(1):1-13.

26. Banwat $M$, et al. Community based health insurance knowledge and willingness to pay; a survey of a rural community in North Central zone of Nigeria. Jos J Med. 2012;6(1):54-9.

27. Noubiap JJN, et al. Community-based health insurance knowledge, concern, preferences, and financial planning for health care among informal sector workers in a health district of Douala, Cameroon. Pan Afr Med J. 2013;16:17.

28. Oo WM, et al. Awareness and acceptance on health insurance, and willingness to pay: a community based study in Myanmar. Adv Trop Med Public Health Int. 2015;5(3):44-51.

29. Zhang $L$, et al. Social capital and farmer's willingness-to-join a newly established community-based health insurance in rural China. Health Policy. 2006;76(2):233-42.

30. Adams R, Chou Y-J, Pu C. Willingness to participate and pay for a proposed national health insurance in St. Vincent and the grenadines: a cross-sectional contingent valuation approach. BMC Health Services Res. 2015;15:148.

Ready to submit your research? Choose BMC and benefit from

- fast, convenient online submission

- thorough peer review by experienced researchers in your field

- rapid publication on acceptance

- support for research data, including large and complex data types

- gold Open Access which fosters wider collaboration and increased citations

- maximum visibility for your research: over 100M website views per year

At BMC, research is always in progress.

Learn more biomedcentral.com/submissions 